Cite this: J. Mater. Chem. A, 2014, 2 , 5716

Received 7th January 2014

Accepted 5th February 2014

DOI: $10.1039 / c 4 t a 00108 \mathrm{~g}$

www.rsc.org/MaterialsA

\section{In situ formation of LDH membranes of different microstructures with molecular sieve gas selectivity $\dagger$}

\begin{abstract}
Yi Liu, N Nanyi Wang and Jürgen Caro*
Research on interlayer gallery-based gas and liquid separation has gained widespread attention. A series of layered materials like lamellar ZSM-5, graphene and its derivatives have been fabricated into membranes showing fascinating gas/liquid separation properties. Layered double hydroxides (LDHs) are prominent representatives of layered compounds composed of regularly arranged brucite-like 2D sheets. Here we successfully prepared well-intergrown NiAl- $\mathrm{CO}_{3} \mathrm{LDH}$ membranes in one step. Particularly it was found that $\mathrm{CO}_{2}$ dissolved in the precursor solution exerted great influence on the microstructure of prepared membranes. Trace amounts of $\mathrm{CO}_{2}$ in the precursor solution led to the formation of ab-oriented $0.6 \mu \mathrm{m}$ thick LDH membranes, while randomly oriented $5 \mu \mathrm{m}$ thick $\mathrm{LDH}$ membranes formed from $\mathrm{CO}_{2^{-}}$ saturated precursor solutions. Both ab- \& randomly oriented LDH membranes showed clear size-based selectivity and $\mathrm{H}_{2}$ was found to preferentially permeate through the interlayer galleries. However, randomly oriented LDH membranes showed a much higher $\mathrm{H}_{2}$ selectivity possibly due to the decreased density of mesoscopic defects. Furthermore, in addition to the NiAl- $\mathrm{CO}_{3} \mathrm{LDH}$ membrane, a compact and randomly oriented $\mathrm{ZnAl}-\mathrm{NO}_{3} \mathrm{LDH}$ membrane with reasonable gas selectivity was successfully prepared here by proper optimization of the synthesis conditions.
\end{abstract}

\section{Introduction}

Microporous membranes with pore apertures below the nanolevel can exhibit size selectivity by serving as molecular sieves, showing significant potential for energy-efficient and environmentally benign separation of gas mixtures. Zeolites, ${ }^{\mathbf{1 - 3}}$ silica, ${ }^{\mathbf{4}}$ carbon, ${ }^{5}$ polymers ${ }^{6}$ and the recently developed metal-organic frameworks (MOFs) ${ }^{7-9}$ have been prepared as microporous membranes showing promising gas mixture separation performance. Since the pioneering work on the lamellar ZSM-5 membrane by M. Tsapatsis et al., ${ }^{\mathbf{1 0}}$ fabrication of membranes from atom-thick two-dimensional (2D) lamellar inorganic sheets has become a frontier research topic of inorganic

Institute of Physical Chemistry and Electrochemistry, Leibniz University Hannover, Callinstr.3A, D-30167 Hannover, Germany.E-mail: yi.liu@pci.uni-hannover.de; juergen.caro@pci.uni-hannover.de

$\dagger$ Electronic supplementary information (ESI) available: EDXS results of the cross-section of the $a b$-oriented NiAl- $\mathrm{CO}_{3} \mathrm{LDH}$ membrane (SI-1), XRD pattern of NiAl- $\mathrm{CO}_{3} \mathrm{LDH}$ powders (SI-2), EDXS results of the front side of the randomly oriented NiAl- $\mathrm{CO}_{3} \mathrm{LDH}$ membrane (SI-3), calculation of the concentration of $\mathrm{CO}_{2}$ in aged de-ionized water and $\mathrm{CO}_{2}$-saturated water solvent (SI-4), high resolution of the cross-sectional image of the randomly oriented LDH membrane (SI-5), demonstration of the gas separation equipment (SI-6), detailed information on the composition and flux of feed, retentate and permeate (SI-7), relationship between the operation temperature and the gas separation performance of the $\mathrm{ZnAl}-\mathrm{NO}_{3} \mathrm{LDH}$ membrane (SI-8) and thermal stability of the prepared $\mathrm{ZnAl}-\mathrm{NO}_{3}$ LDH membrane (SI-9). See DOI: 10.1039/c4ta00108g membranes. In principle, membranes constructed from inorganic 2D sheets can be one atom thick, enabling minimization of the transport resistance and maximization of the flux. Additionally, they can be more mechanically flexible.

Graphene and its derivatives are representatives of $2 \mathrm{D}$ layered materials. J. S. Bunch et al. first demonstrated that graphene can serve as a gas molecular sieve membrane through ultraviolet-induced oxidative etching. ${ }^{11} \mathrm{M}$. Yu et al. reported the fabrication of ultrathin graphene oxide (GO) membranes with thickness approaching $1.8 \mathrm{~nm}$ by a facile filtration process. The membrane showed a $\mathrm{H}_{2}-\mathrm{CO}_{2}$ mixed selectivity as high as $3400{ }^{12}$ The reduction experiment proved that structural defects within GO flakes rather than the interlayer galleries contributed to the selective permeation of $\mathrm{H}_{2}$. Nevertheless, GO membranes prepared by H. W. Yoon and S.-M. Yoon showed humiditydependent mixed gas selectivity in favour of $\mathrm{CO}_{2}$ which, as admitted by authors, may result from the particular molecular transport pathways through the interlayer galleries. ${ }^{13}$ Due to the irregular stacking caused by corrugations, wrinkles and ripples, randomly stacked GO sheets had a broad spacing distribution, and the gas permeation behaviour was mainly dominated by Knudsen diffusion except for $\mathrm{CO}_{2}$ molecules. This condition could be improved by proper optimization of the fabrication process. The potential of interlayer spacing for size-based separation, however, is still rarely explored so far.

Layered double hydroxides (LDHs), which have the general formula $\left[\mathrm{M}_{1-x}{ }^{2+} \mathrm{M}_{x}{ }^{3+}(\mathrm{OH})_{2}\right]\left[\mathrm{A}^{n-}\right]_{x / n} \cdot z \mathrm{H}_{2} \mathrm{O}\left(\mathrm{M}^{2+}, \mathrm{M}^{3+}, \mathrm{A}^{n-}\right.$ and 
$\mathrm{H}_{2} \mathrm{O}$ represent di- and tri-valent metal ions, $n$-valent anions and the interlayer water, respectively), are typical representatives of crystalline layered compounds. Metal cations are located in the centre of edge sharing octahedra, whose vertices contain hydroxide ions that connect to form infinite brucite-like 2D layers. ${ }^{14}$ LDHs consist of regularly arranged, positively charged brucite-like 2D layers and charge compensating anions located in interlayer galleries. ${ }^{15}$ Compositional flexibility in both the positively charged layers and charge-balancing anions gives rise to a functional diversity. ${ }^{16}$ Unlike stacked graphene or GO sheets, the interlayer spacing of LDHs is highly uniform and adjustable by proper selection of charge compensating anions. So it is a great opportunity to explore their potential as separation membranes.

With the vacuum-suction method, T. T. Tsotsis first prepared $\mathrm{MgAl}-\mathrm{CO}_{3}$ hydrotalcite membranes with an ideal selectivity of pairs of inert gases higher than their Knudsen values. ${ }^{17}$ Nevertheless, there were substantial mesoporous voids and pinholes in prepared membranes which comprised their gas selectivity. ${ }^{17 c}$ Therefore, one may expect a significantly improved gas separation performance in case mesoporous regions were completely plugged. Very recently, we reported the in situ hydrothermal growth of a compact NiAl- $\mathrm{CO}_{3} \mathrm{LDH}$ membrane on a $\gamma-\mathrm{Al}_{2} \mathrm{O}_{3}$ substrate. ${ }^{18}$ This carbonate-intercalated layered membrane had a uniform gallery height of $0.31 \mathrm{~nm}$, which was smaller than the kinetic diameter of most gas molecules except $\mathrm{H}_{2} \quad(0.29 \mathrm{~nm})$. Correspondingly, the prepared membrane showed remarkable molecular sieve property and the separation factor (SF) towards a $\mathrm{H}_{2}-\mathrm{CH}_{4}$ mixture reached $\sim 80$ (schematically shown in Fig. 1). Moreover, different from graphene or GO membrane fabrication, the formation of brucite-like 2D sheets, their self-assembly into LDH crystallites and their attachment to the substrate were completed in one step.

Due to the high affinity of carbonate anions $\left(\mathrm{CO}_{3}{ }^{2-}\right)$ to brucite-like $2 \mathrm{D}$ layers, preparations have to be made in a glove box or alternatively, prior to LDH synthesis, the precursor solution is usually bubbled with inert gas ( $\mathrm{such}$ as $\mathrm{N}_{2}$ ) to eliminate the dissolved $\mathrm{CO}_{2}$ for minimizing the intercalation of unwanted $\mathrm{CO}_{3}{ }^{2-} \cdot{ }^{19}$ In this study, however, we found that $\mathrm{CO}_{2}$ could be a powerful tool to manipulate the microstructure (including

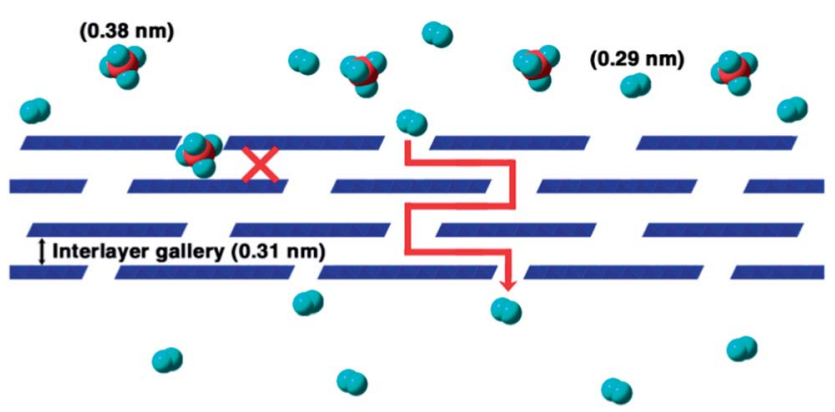

Fig. 1 Schematic illustration of the concept of interlayer gallery-based separation. In the figure, layered compounds with a gallery height of $0.31 \mathrm{~nm}$ represent $\mathrm{NiAl}-\mathrm{CO}_{3} \mathrm{LDH}$ membranes as mentioned below. Gas molecules with kinetic diameters of $0.29 \mathrm{~nm}$ and $0.38 \mathrm{~nm}$ represent $\mathrm{H}_{2}$ and $\mathrm{CH}_{4}$, respectively. preferred orientation, thickness and grain boundaries) and thus the gas permeation behavior of prepared $\mathrm{NiAl}-\mathrm{CO}_{3} \mathrm{LDH}$ membranes. Several unique experimental observations such as the selective intercalation of $\mathrm{CO}_{2}$ to the interlayer space, the preferred $a b$-orientation and almost a 3-fold decrease of $\mathrm{H}_{2}$ permeance in the $\mathrm{H}_{2}-\mathrm{CO}_{2}$ mixture were found and further discussed. With this method, a high quality $\mathrm{ZnAl}-\mathrm{NO}_{3} \mathrm{LDH}$ membrane with a gallery height of $0.42 \mathrm{~nm}$ was further fabricated showing considerable hydrogen selectivity.

\section{Experimental}

\section{Preparation of NiAl-LDH membranes}

Asymmetric porous $\mathrm{Al}_{2} \mathrm{O}_{3}$ substrates were supplied by Fraunhofer IKTS. The diameter and thickness of the substrate were $18 \mathrm{~mm}$ and $1 \mathrm{~mm}$, respectively. Before in situ growth, a $\gamma-\mathrm{Al}_{2} \mathrm{O}_{3}$ intermediate layer was deposited onto the porous alumina substrate using the method developed by Zhang et al. ${ }^{20}$

The precursor solution was prepared by adding $5.8 \mathrm{~g}$ $\mathrm{Ni}\left(\mathrm{NO}_{3}\right)_{2} \cdot 6 \mathrm{H}_{2} \mathrm{O}$ (98.0 wt\%, Aldrich) and $4.8 \mathrm{~g} \mathrm{NH}_{4} \mathrm{NO}_{3}$ (98.0 wt

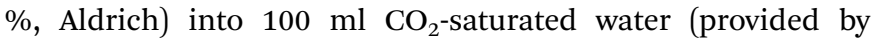
Vitalitasia Classic with saturated $\mathrm{CO}_{2}$ ). Then $10 \mathrm{ml} 1 \mathrm{wt} \%$ $\mathrm{NH}_{3} \cdot \mathrm{H}_{2} \mathrm{O}$ (Aldrich) was added dropwise into the aqueous solution and stirred in an ice bath for $10 \mathrm{~min}$. Besides $\mathrm{CO}_{2}$ saturated water, deionized (DI) water was also used as a solvent to prepare $\mathrm{LDH}$ membranes following the same procedure and recipe as shown above. Attention: DI water had to be aged in open air for at least 1 month to reach equilibrium of the dissolved $\mathrm{CO}_{2}$ with the surrounding atmosphere.

The $\gamma-\mathrm{Al}_{2} \mathrm{O}_{3}$ modified alumina substrate was vertically placed into a $50 \mathrm{ml}$ Teflon-lined stainless steel vessel. Then $35 \mathrm{ml}$ of the precursor solution was poured into the vessel and sealed. The vessel was put into a convective oven pre-heated at $85^{\circ} \mathrm{C}$. After an elapsed time of $40 \mathrm{~h}$, the membrane was taken out, washed with copious of DI water and dried in a convective oven at $60{ }^{\circ} \mathrm{C}$ for $12 \mathrm{~h}$.

\section{Preparation of the ZnAl-LDH membrane}

The precursor solution was prepared by mixing $6.0 \mathrm{~g}$ $\mathrm{Zn}\left(\mathrm{NO}_{3}\right)_{2} \cdot 6 \mathrm{H}_{2} \mathrm{O}$ (98.0 wt\%, Aldrich), $4.8 \mathrm{~g} \mathrm{NH} \mathrm{NO}_{3}$ (98.0 wt\%, Aldrich) and $0.8 \mathrm{~g}$ glycine sodium (98.0 wt\%, Acros) into $100 \mathrm{ml}$ DI water. Then $10 \mathrm{ml} 1 \mathrm{wt} \% \mathrm{NH}_{3} \cdot \mathrm{H}_{2} \mathrm{O}$ (Aldrich) was added dropwise into the aqueous solution and stirred at room temperature for $10 \mathrm{~min}$.

The $\mathrm{ZnAl}-\mathrm{LDH}$ membrane was in situ grown on the $\gamma-\mathrm{Al}_{2} \mathrm{O}_{3}$ modified $\alpha-\mathrm{Al}_{2} \mathrm{O}_{3}$ substrate as in the case of the NiAl-LDH membrane except that the synthesis temperature was set at $65{ }^{\circ} \mathrm{C}$ for $40 \mathrm{~h}$.

\section{Characterization}

XRD was carried out on a Philips-PW1710 diffractometer with $\mathrm{CuK}_{\alpha}$ radiation (wavelengths $\lambda=0.154 \mathrm{~nm}$ ). The SEM images were taken on a JEOL JSM-6700F field-emission scanning electron microscope (FEI) with an accelerating voltage of $2 \mathrm{kV}$, a $10 \mu \mathrm{A}$ current and a working distance of $8 \mathrm{~mm}$. 


\section{Gas permeation experiment}

For mixed gas permeation measurements, the prepared LDH membrane was fixed in a module sealed with high-temperatureresistant silicone O-rings. A 1 : 1 mixture of gas was applied to the feed side of the membrane, and the permeated gas was removed from the permeate side by sweep gas. The feed flow rate was kept constant with a total volumetric flow rate of $100 \mathrm{ml}$ $\min ^{-1}$ (each gas of $50 \mathrm{ml} \mathrm{min}{ }^{-1}$ ). The permeate flow rate was kept at $50 \mathrm{ml} \mathrm{min}^{-1}$. Pressures at both feed side and permeate side were kept at 1 bar. In most cases, $\mathrm{N}_{2}$ was used as sweep gas, except in the $\mathrm{H}_{2}-\mathrm{N}_{2}$ measurement, where $\mathrm{CH}_{4}$ was employed as the sweep gas.

A calibrated gas chromatograph (HP7890a) was used to measure the concentration of gas mixtures on the permeate side. The separation factor $\alpha_{i / j}$ of a binary gas mixture is defined as the quotient of the molar ratios of the components $(i, j)$ in the permeate side, divided by the quotient of the molar ratio of the components $(i, j)$ on the feed side:

$$
\alpha_{i / j}=\frac{x_{i, \text { perm }} / x_{j, \text { perm }}}{x_{i, \text { feed }} / x_{j, \text { feed }}}
$$

\section{Results and discussion}

Our experimental findings showed that the concentration of dissolved $\mathrm{CO}_{2}$ in the precursor solution exerted great influence on the microstructure of prepared NiAl- $\mathrm{CO}_{3} \mathrm{LDH}$ membranes. With aged DI water which contains a low $\mathrm{CO}_{2}$ concentration as solvent (shown in Fig. 2a), after in situ hydrothermal growth, the substrate surface had been fully covered with closely packed LDH crystallites which spontaneously formed a compact LDH layer. Nevertheless, nano-cracks appeared and spread through the surface of the LDH layer (white arrows in Fig. 2a). The crosssectional image revealed that the membrane is uniform with a
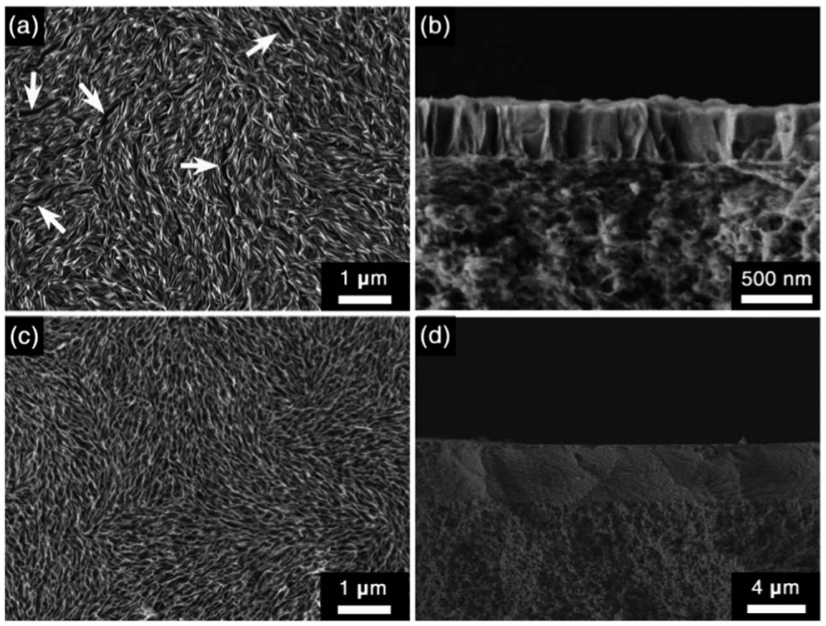

Fig. 2 SEM images of $\mathrm{NiAl}-\mathrm{CO}_{3}$ layered double hydroxide (LDH) membranes prepared with ( $a$ and b) DI water and (c and d) $\mathrm{CO}_{2}^{-}$ saturated water as solvents, respectively. White arrows denote nanocracks on the surface of the LDH layer. thickness of $\sim 0.6 \mu \mathrm{m}$, and $\mathrm{LDH}$ crystallites tended to grow preferentially with their $a b$-direction (the largest faces) perpendicular to the substrate. The XRD pattern of the membrane showed two observable diffraction peaks at $2 \theta$ values of $11.2^{\circ}$ and $35.1^{\circ}$ which could be assigned to reflections of $(0$ $\left.\begin{array}{lll}0 & 3\end{array}\right)$ and ( $\left(\begin{array}{lll}0 & 1 & 2\end{array}\right)$ crystal planes of the LDH phase (Fig. 3a). However, the intensity of the $\left(\begin{array}{lll}0 & 0 & 3\end{array}\right)$ diffraction peak was much weaker than that of the $\left(\begin{array}{lll}0 & 1 & 2\end{array}\right)$ diffraction peak. This phenomenon further confirmed that most LDH crystallites indeed were arranged with their $a b$-faces perpendicular to the substrate, as schematically shown in the inset of Fig. 3a. Due to the severe peak overlap between the substrate and the LDH phase, it was difficult to accurately identify all diffraction peaks derived from the LDH layer. Additionally, the detection of Ni element within the substrate pores as observed from the energy-dispersive X-ray spectroscopy (EDXS, Fig. 4b) of the cross-section of the $a b$ oriented $\mathrm{LDH}$ membrane (Fig. 4a) revealed that $\mathrm{Ni}^{2+}$ readily diffused into the support pores and gave rise to the formation of additional NiAl LDH crystallites within the substrate pores, which could be discerned from their plate-like morphology (shown in the inset of Fig. 4b) characteristic of layered compounds. Also the detection of element $\mathrm{C}$ within the substrate pores demonstrated the presence of the carbonate intercalated NiAl LDH phase (SI-1†). These LDHs embedded into the support may partially contribute to the size-based separation of gas mixtures as had been observed in zeolite membranes synthesized via the pore-plugging approach. ${ }^{21}$

In contrast, the $\mathrm{LDH}$ membrane synthesized from the $\mathrm{CO}_{2}$ saturated $\mathrm{H}_{2} \mathrm{O}$ was more compact. Unlike the $\mathrm{LDH}$ membrane prepared with aged DI water as a solvent, no conspicuous cracks were observed (Fig. 2c). The cross-sectional image illustrated that the LDH layer was $\sim 5 \mu \mathrm{m}$ thick (Fig. $2 \mathrm{~d}$ ). The prepared LDH membrane showed three observable diffraction peaks at $2 \theta$

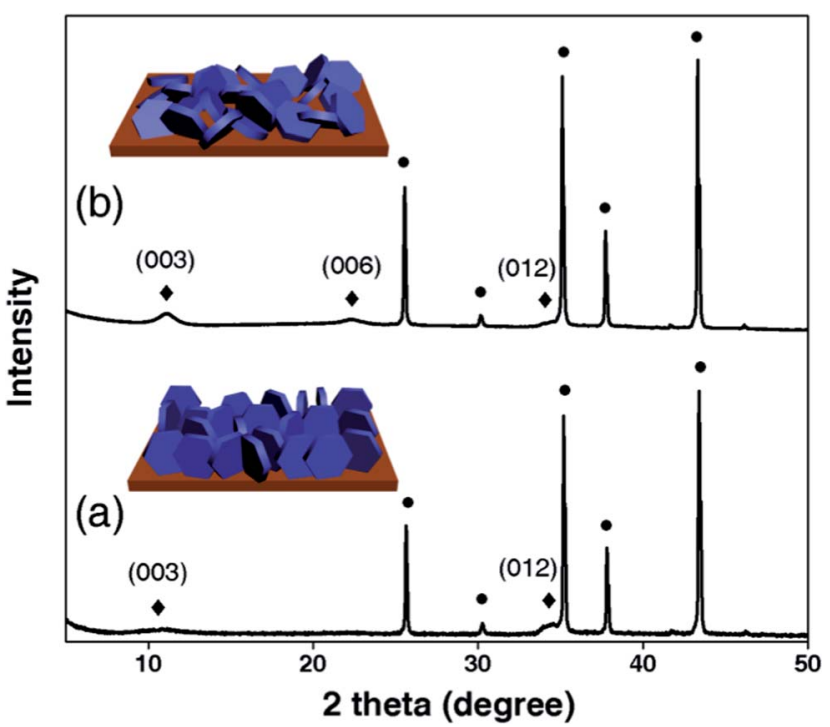

Fig. 3 XRD patterns of $\mathrm{NiAl}-\mathrm{CO}_{3} \mathrm{LDH}$ membranes prepared with (a) $\mathrm{DI}$ water and (b) $\mathrm{CO}_{2}$-saturated water as solvents, respectively. Inset: schematic illustration of the microstructure of each LDH membrane based on the XRD pattern and SEM image. 


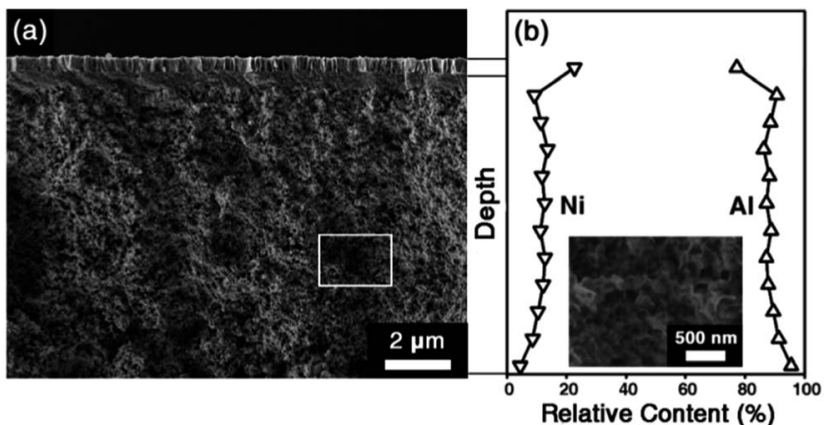

Fig. 4 (a) SEM image and (b) EDXS map of the cross-section of the $a b$ oriented $\mathrm{NiAl}-\mathrm{CO}_{3} \mathrm{LDH}$ membrane. Inset of (b): an enlarged image of the cross-sectional image of the substrate obtained from (a) (the rectangular frame).

values of $11.2^{\circ}, 22.3^{\circ}$ and $35.1^{\circ}$, respectively, which were characteristic of the reflections of ( $\left(\begin{array}{lll}0 & 0 & 3\end{array}\right),\left(\begin{array}{lll}0 & 0 & 6\end{array}\right)$ and $\left(\begin{array}{lll}0 & 1 & 2\end{array}\right)$ crystal planes of the $\mathrm{LDH}$ layer. It should be noted that in contrast to the above-mentioned $a b$-oriented LDH membrane, the relative intensity of these peaks was consistent with the XRD patterns of randomly oriented $\mathrm{LDH}$ powders (SI-2 $\dagger$ ) thus indicating that this LDH membrane was randomly oriented (shown in the inset of Fig. 3b). EDXS of the NiAl LDH layer of the membrane indisputably confirmed that $\mathrm{CO}_{3}{ }^{2-}$ served as the chargecompensating anions (as shown in SI- $3 \dagger$ ). Similar to the $a b$ oriented LDH membrane, some LDH crystallites were also crystallized within the substrate pores of the randomly oriented LDH membrane (not shown here).

The $d_{(003)}$-spacing, which can be calculated according to the Bragg equation, equals the interlayer spacing of LDHs. ${ }^{22}$ In this study, ( $\left.\begin{array}{lll}0 & 0 & 3\end{array}\right)$ diffraction peaks of both LDH membranes appeared at a $2 \theta$ value of $11.2^{\circ}$, which corresponded to an interlayer distance of $0.79 \mathrm{~nm}$. This value coincided well with the values in the literature for $\mathrm{LDH}$ materials with interlayer $\mathrm{CO}_{3}{ }^{2-}$ anions converted from the dissolved $\mathrm{CO}_{2}$ in the precursor solutions. ${ }^{22} \mathrm{X}$. Duan et al. also observed this interesting phenomenon in the synthesis of $\mathrm{NiAl} \mathrm{LDH}$ films on porous anodic alumina/aluminium (PAO/Al) substrates and proposed a heterogeneous nucleation mechanism which could be applied and extended here to interpret why carbonate rather than more abundant nitrate anions were incorporated into the interlayer space: ${ }^{23}$ after being exposed to the precursor solution, the $\gamma-\mathrm{Al}_{2} \mathrm{O}_{3}$ intermediate layer coated on the substrate was spontaneously converted into a highly chemically active hydrated aluminum hydroxide gel. Then nucleation of $\mathrm{LDH}$ crystallites occurred at the gel-solution interface where both the $\mathrm{Ni}^{2+}$ and $\mathrm{Al}^{3+}$ were present. Finally the growth of $\mathrm{LDH}$ crystallites gradually proceeded into the gel towards the substrate until a closed LDH layer was formed. Synthesis of the LDH phase involved the intercalation of charge compensating anions into the interlayer space of neighboring brucite-like 2D sheets. The eventual selective incorporation of carbonate instead of nitrate into $\mathrm{LDH}$ frameworks can be attributed to the (1) much faster diffusion of $\mathrm{CO}_{2}$ molecules into the gel than that of nitrate anions, and to the (2) high affinity of carbonate anions to positively charged brucite-like $2 \mathrm{D}$ sheets. ${ }^{24}$ The ion-exchange equilibrium constants of anions for LDHs are in the sequence $\mathrm{CO}_{3}{ }^{2-}>\mathrm{SO}_{4}{ }^{2-}>\mathrm{OH}^{-}>\mathrm{F}^{-}>\mathrm{Cl}^{-}>\mathrm{Br}^{-}>\mathrm{NO}_{3}{ }^{-}>\mathrm{I}^{-}$which explains why $\mathrm{NO}_{3}{ }^{-}$anions are exchanged by $\mathrm{CO}_{3}{ }^{2-}$.

The preferred $a b$-orientation of the LDH membrane could be interpreted by the "evolution selection" growth mechanism, which was developed by Van der Drift in interpretation of the preferred orientation of a vapor-deposited PbO layer. ${ }^{25}$ In an early stage, crystal nuclei evolved in all possible crystallographic axes. However, in case that the growth rate along each crystallographic direction was different, for each crystal, the direction with the fastest growth rate would incline to the surface of the substrate at a different angle. When two crystals met, the more steeply growing crystal would prevent the further growth of the less steeply growing crystal. Eventually, crystals with the fastest growth direction normal to the substrate would cover neighboring crystals and became dominant in the layer. Since the growth rate along the $a b$-direction was much faster than that along the $c$-direction for anisotropic LDH crystals, after in situ growth, the $a b$-faces of LDH crystallites would spontaneously arrange in a direction perpendicular to the substrate. ${ }^{26}$ It should be emphasized that the preferential orientation during crystal growth on substrates is very common and has been observed for a variety of other crystalline materials like $\mathrm{ZnO},{ }^{27}$ zeolites $^{\mathbf{1 , 2 8}}$ and metal organic frameworks (MOFs). ${ }^{29}$

According to Henry's law, the concentration of $\mathrm{CO}_{2}$ dissolved in aged DI water and in $\mathrm{CO}_{2}$-saturated water was estimated to be $\sim 1.3 \times 10^{-5} \mathrm{M}$ and $\sim 3.3 \times 10^{-2} \mathrm{M}$, respectively (details are shown in SI-4 $\dagger$ ). As mentioned above, dissolved $\mathrm{CO}_{2}$ served as the precursor of $\mathrm{CO}_{3}{ }^{2-}$ anions which were then selectively intercalated into the interlayer space of brucite-like 2D sheets. Since the $\mathrm{CO}_{2}$-saturated water solvent contained much higher concentration of $\mathrm{CO}_{2}$, it was reasonable to assume that during the in situ growth, the nucleation density of LDHs on the substrate was much higher and their growth rate was greatly accelerated. As a result, a well-intergrown NiAl- $\mathrm{CO}_{3} \mathrm{LDH}$ layer was prepared even before LDH crystallites with plate-like shape were formed (experimental evidence is shown in SI-5 $\dagger$ ). This model properly explained why the $\mathrm{LDH}$ membrane prepared from the $\mathrm{CO}_{2}$-saturated water solvent was randomly oriented. A

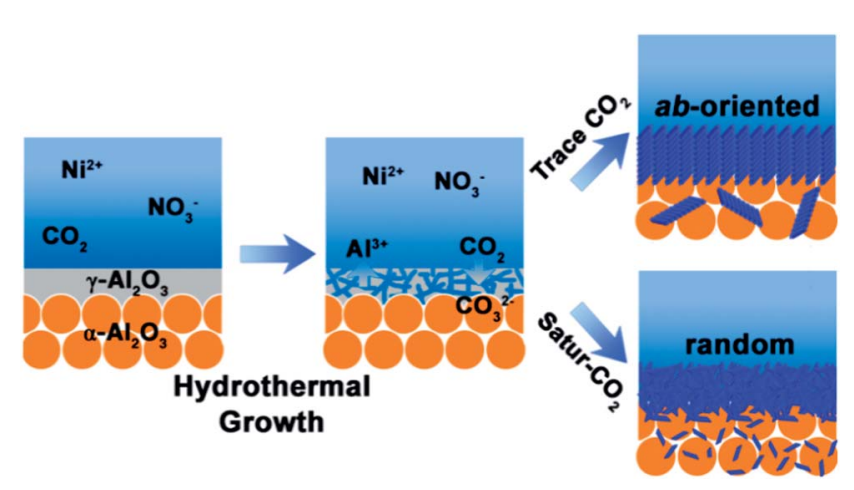

Fig. 5 Schematic illustration of the in situ hydrothermal growth of $\mathrm{NiAl}-\mathrm{CO}_{3} \mathrm{LDH}$ membranes with diverse microstructures. $\mathrm{CO}_{2}$ plays an important role in controlling the preferred orientation of the $\mathrm{NiAl}-\mathrm{CO}_{3}$ LDH crystals in the membranes. 
schematic illustration of formation processes of $a b$ - \& randomly oriented LDH membranes is shown in Fig. 5.

By subtracting the thickness of a brucite-like layer, i.e. $0.48 \mathrm{~nm}$ well-known in the field of $\mathrm{LDHs},{ }^{30}$ the interlayer gallery for carbonate intercalated $\mathrm{LDH}$ was estimated to be $0.31 \mathrm{~nm}$, which was smaller than the kinetic diameters of most gas molecules like $\mathrm{CO}_{2}(0.33 \mathrm{~nm}), \mathrm{N}_{2}(0.36 \mathrm{~nm})$ and $\mathrm{CH}_{4}(0.38 \mathrm{~nm})$ except $\mathrm{H}_{2}(0.29 \mathrm{~nm})$. It was thus anticipated that for a gas mixture containing hydrogen, $\mathrm{H}_{2}$ would preferentially pass through the interlayer galleries of the LDH layer and become separated from the mixture via a molecular sieve mechanism.

Both $a b$ - \& randomly oriented NiAl LDH membranes were initially impermeable to any gases since the interlayer space was still occupied with solvent $\left(\mathrm{H}_{2} \mathrm{O}\right)$ molecules, which blocked the diffusion routes of guest molecules (schematically shown in Fig. 6). To open the interlayer galleries, on-stream thermal activation was carried out by using a Wicke-Kallenbach permeation cell with a $1: 1$ mixture of $\mathrm{H}_{2}$ and $\mathrm{CH}_{4}$ on the feed side and $\mathrm{N}_{2}$ on the permeate side as sweeping gas (shown in SI- $6 \dagger$ ). After activation, permeances of $\mathrm{H}_{2}-\mathrm{CO}_{2}, \mathrm{H}_{2}-\mathrm{N}_{2}$ and $\mathrm{H}_{2}-$ $\mathrm{CH}_{4}$ as 1 : 1 mixtures were measured on both $\mathrm{LDH}$ membranes at $180{ }^{\circ} \mathrm{C}$ and $1 \mathrm{bar}$, and the mixed gas permeation results are shown in Table 1 (detailed information on the composition and flux of feed, retentate and permeate during the gas permeability tests is shown in SI-7 $\dagger$ ). For an $a b$-oriented LDH membrane, the separation factors (SF) of $\mathrm{H}_{2}-\mathrm{CO}_{2}, \mathrm{H}_{2}-\mathrm{N}_{2}$ and $\mathrm{H}_{2}-\mathrm{CH}_{4}$ mixtures

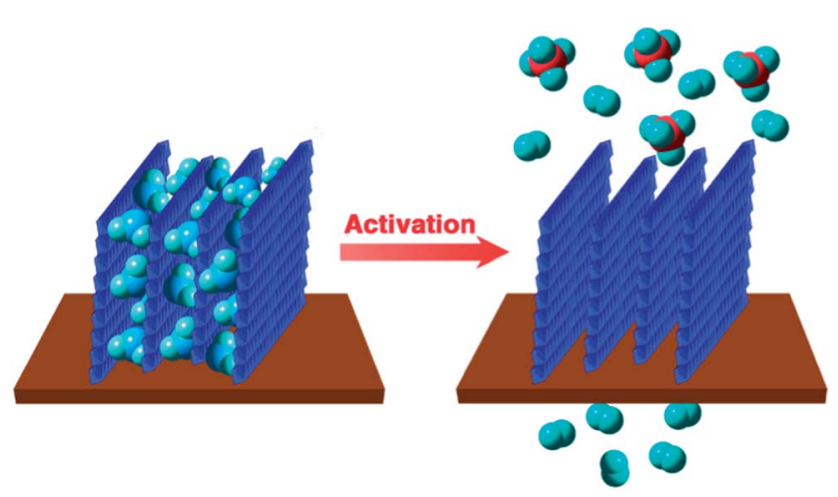

Fig. 6 Schematic illustration of the thermal activation of as-prepared LDH membranes. Initially LDH membranes are impermeable to any gases since interlayer galleries still contain the solvent molecules $\left(\mathrm{H}_{2} \mathrm{O}\right)$.

Table $1 \mathrm{H}_{2}$ permeances and SF of $\mathrm{H}_{2}-\mathrm{CO}_{2}, \mathrm{H}_{2}-\mathrm{N}_{2}$ and $\mathrm{H}_{2}-\mathrm{CH}_{4}$ mixtures on $a b$-oriented and randomly oriented $\mathrm{NiAl}-\mathrm{CO}_{3} \mathrm{LDH}$ membranes, respectively. Operation temperature: $180{ }^{\circ} \mathrm{C}$; feed pressure: 1 bar

\begin{tabular}{llll}
\hline & Aged DI water & $\mathrm{CO}_{2}$-saturated water \\
\cline { 2 - 3 } & $\begin{array}{l}\mathrm{H}_{2} \text { permeance } \\
\left(10^{-8} \mathrm{~mol} \mathrm{~m}^{-2} \mathrm{~s}^{-1} \mathrm{~Pa}^{-1}\right)\end{array}$ & $\mathrm{SF}$ & $\begin{array}{l}\mathrm{H}_{2} \text { permeance } \\
\left(10^{-8} \mathrm{~mol} \mathrm{~m}^{-2} \mathrm{~s}^{-1} \mathrm{~Pa}^{-1}\right) \mathrm{SF}\end{array}$ \\
\hline
\end{tabular}

$\mathrm{H}_{2}-\mathrm{CO}_{2} \quad 5.0$

$\begin{array}{ll}5.8 & 1.7\end{array}$

10.7

$\mathrm{H}_{2}-\mathrm{N}_{2} \quad 5.4$

$8.2 \quad 4.4$

$\mathrm{H}_{2}-\mathrm{CH}_{4} \quad 5.7$ reached 5.8, 8.2 and 8.8, respectively, which were all considerably higher than their Knudsen values (4.7, 3.7 and 2.8). This experimental finding was an indication of the domination of a molecular sieve mechanism. For a randomly oriented $\mathrm{LDH}$ membrane, the SF of $\mathrm{H}_{2}-\mathrm{CO}_{2}, \mathrm{H}_{2}-\mathrm{N}_{2}$ and $\mathrm{H}_{2}-\mathrm{CH}_{4}$ binary mixtures further increased to $10.7,18.1$ and 78.7, respectively. Initially, an $a b$-oriented $\mathrm{LDH}$ membrane was expected to be more suitable for gas permeation since the interlayer galleries were arranged perpendicular to the substrate which was favorable to minimize the mass transfer resistance. Nevertheless, the high length-to-width ratio of LDH crystallites and the insufficient supply of $\mathrm{CO}_{2}$ possibly led to the formation of mesoscopic defects within the LDH layer, which had comprised their gas separation performance. In contrast, randomly oriented LDH membranes showed much higher $\mathrm{H}_{2}$ selectivity due to the better intergrowth between the LDH crystallites and sufficient supply of dissolved $\mathrm{CO}_{2}$ in the precursor solution. An in-depth investigation into the gas separation performance of the randomly oriented $\mathrm{NiAl}-\mathrm{CO}_{3} \mathrm{LDH}$ membrane has been carried out recently in our lab. ${ }^{18}$

It should be noted that compared with $\mathrm{H}_{2}-\mathrm{N}_{2}$ or $\mathrm{H}_{2}-\mathrm{CH}_{4}$ mixtures, there was almost a 3-fold decrease of the $\mathrm{H}_{2}$ permeance in the $\mathrm{H}_{2}-\mathrm{CO}_{2}$ mixture $\left(1.7 \times 10^{-8} \mathrm{~mol} \mathrm{~m}^{-2} \mathrm{~s}^{-1} \mathrm{~Pa}^{-1}\right)$. The sharp decrease of the $\mathrm{H}_{2}$ permeance could be interpreted by considering the strong interplay between $\mathrm{CO}_{2}$ molecules and the NiAl brucite-like 2D layers. LDHs have been considered as $\mathrm{CO}_{2}$ selective adsorbents. ${ }^{31}$ Moreover, recently it has been demonstrated that $\mathrm{CO}_{3}{ }^{2-}$ anions intercalated within LDHs could even undergo a dynamic exchange with $\mathrm{CO}_{3}{ }^{2-}$ anions derived from atmospheric $\mathrm{CO}_{2}$ under ambient conditions. ${ }^{32}$ The adsorption site of $\mathrm{CO}_{2}$ was probably $\mathrm{Ni}-\mathrm{OH}$, where reversible acid-base interactions could occur. Since the gallery height of the prepared NiAl- $\mathrm{CO}_{3} \mathrm{LDH}$ layer was only about $0.31 \mathrm{~nm}$, it was reasonable to assume that $\mathrm{CO}_{2}$ in the gas mixture had severely hindered the permeation of hydrogen through the $\mathrm{LDH}$ membrane. In contrast, for the $a b$-oriented LDH membrane, the $\mathrm{H}_{2}$ permeance was only slightly influenced by the $\mathrm{CO}_{2}$ component, probably due to the existence of mesoscopic defects within the LDH layer. A similar phenomenon was also observed by T. T. Tsostsis et $a .^{17 c}$ and the reported gas selectivity was close to the one of our $a b$-oriented LDH membrane.

It has to be emphasized that interlayer galleries in the LDH layer should be the main diffusion paths of guest molecules. On the one hand, it was well-known from the literature ${ }^{33}$ that for carbonate-intercalated LDHs, the loosely fixed interlayer water was desorbed in the temperature range of 70-190 ${ }^{\circ} \mathrm{C}$. While above $190{ }^{\circ} \mathrm{C}$, the $\mathrm{OH}^{-}$groups in the interlayer began to dehydroxylate, and the dehydroxylation rate was abruptly accelerated if the temperature was increased to $250{ }^{\circ} \mathrm{C}$, leading to an irreversible deformation of the interlayer structure. On the other hand, our recent study ${ }^{\mathbf{1 8}}$ showed that the $\mathrm{NiAl}-\mathrm{CO}_{3} \mathrm{LDH}$ membrane had maximum selectivity for the $\mathrm{H}_{2}-\mathrm{CH}_{4}$ mixture at $180{ }^{\circ} \mathrm{C}$, which was very close to the upper temperature limit required for the removal of the interlayer water (the $\mathrm{H}_{2}-\mathrm{CH}_{4}$ permselectivity was measured at temperatures of 90, 120, 150, 180,210 and $240{ }^{\circ} \mathrm{C}$, respectively). Furthermore, the $\mathrm{NiAl}-\mathrm{CO}_{3}$ LDH membrane could not withstand an operation temperature 
higher than $240{ }^{\circ} \mathrm{C}$, which was the threshold temperature where accelerated dehydroxylation of $\mathrm{OH}^{-}$groups took place. Since the gas permeation behavior of the $\mathrm{NiAl}-\mathrm{CO}_{3} \mathrm{LDH}$ membrane is closely related to the property of the interlayer structure, it is reasonable for us to deduce that guest molecules permeate through the LDH membrane mainly via the interlayer gallery.

The gallery height of the prepared $\mathrm{LDH}$ membrane was adjustable. For instance, it was found that a $\mathrm{ZnAl} \mathrm{LDH}$ membrane could also be grown on the $\gamma-\mathrm{Al}_{2} \mathrm{O}_{3}$ modified porous alumina substrate, provided that $\mathrm{Zn}\left(\mathrm{NO}_{3}\right)_{2}$ instead of $\mathrm{Ni}\left(\mathrm{NO}_{3}\right)_{2}$ was used as the reagent. The XRD pattern of the membrane showed three conspicuous diffraction peaks at $2 \theta$ values of $9.8^{\circ}$, $19.8^{\circ}$ and $33.9^{\circ}$ which could be assigned to reflections of $\left(\begin{array}{lll}0 & 0 & 3\end{array}\right)$, $\left(\begin{array}{lll}0 & 0 & 6\end{array}\right)$ and $\left(\begin{array}{lll}0 & 1 & 2\end{array}\right)$ lattice planes of the LDH phase (Fig. 7). The relative intensities of these peaks were consistent with XRD patterns of LDH powders thus implying that the prepared LDH membrane was randomly oriented. Its $d_{(003)}$-spacing, however, was $0.90 \mathrm{~nm}$, which was equal to the basal spacing of $\mathrm{NO}_{3}{ }^{-}$ intercalated LDHs. ${ }^{34}$ In contrast to the aforementioned NiAl$\mathrm{CO}_{3} \mathrm{LDH}$ membrane, here the preferential intercalation of nitrate anions to the interlayer space of the $\mathrm{ZnAl} \mathrm{LDH}$ phase could be satisfactorily interpreted by assuming a homogenous nucleation mechanism. A more detailed mechanistic study of the selective intercalation of nitrate anions to the $\mathrm{ZnAl} \mathrm{LDH} \mathrm{film}$ has been carried out by X. Duan et al. recently. ${ }^{23}$

Proper optimization of synthesis conditions was indispensable for the preparation of a high quality $\mathrm{ZnAl}-\mathrm{NO}_{3} \mathrm{LDH}$ membrane. In particular it was found that the addition of a given amount of glycine sodium to the precursor solution was beneficial to prepare a compact $\mathrm{ZnAl}-\mathrm{NO}_{3} \mathrm{LDH}$ layer probably due to the better control over the $\mathrm{pH}$ value of the precursor solution. After in situ growth, the substrate was fully covered with closely packed LDH crystallites (Fig. 8a), and no conspicuous cracks on the surface were observed. The cross-sectional image showed that the prepared $\mathrm{ZnAl}-\mathrm{NO}_{3} \mathrm{LDH}$ membrane was uniform with a thickness of $\sim 2.5 \mu \mathrm{m}$ (Fig. 8b).

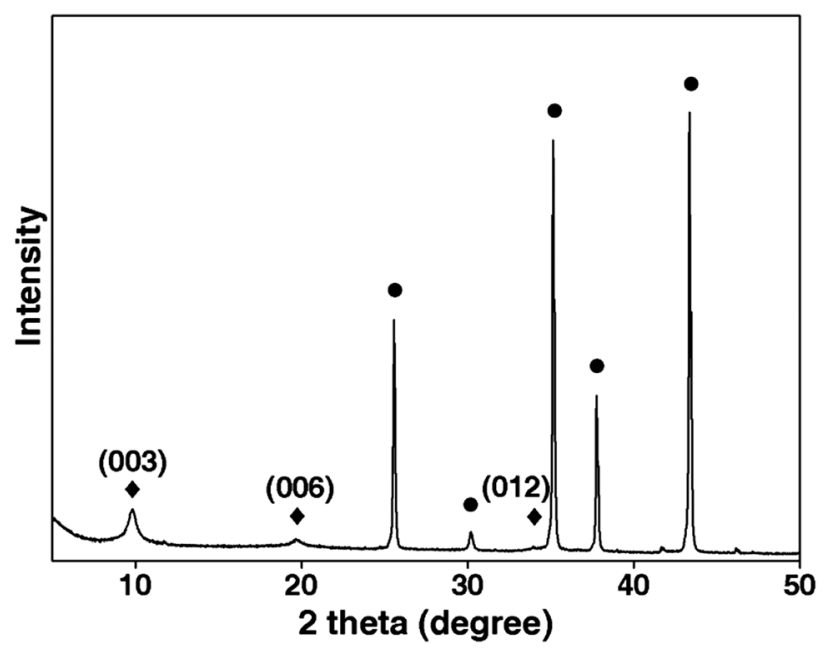

Fig. 7 XRD pattern of the prepared $\mathrm{ZnAl}-\mathrm{NO}_{3} \mathrm{LDH}$ membrane. Peaks marked with black dots and black rhombuses represent the diffraction peaks from substrate and LDH phase, respectively.
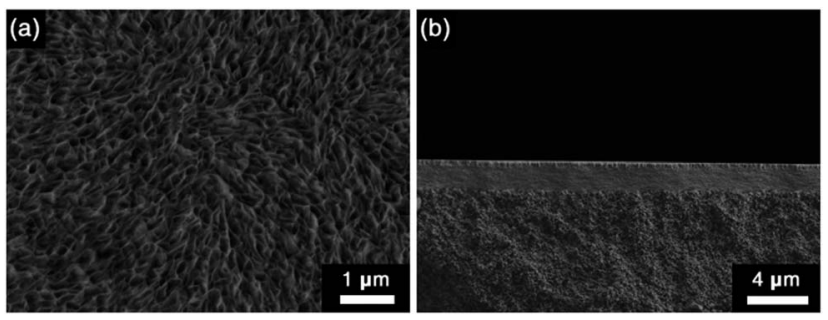

Fig. 8 The (a) top and (b) cross-sectional SEM images of the prepared $\mathrm{ZnAl}-\mathrm{NO}_{3} \mathrm{LDH}$ membrane.

We further measured the gas permeation behavior of the $\mathrm{ZnAl}-\mathrm{NO}_{3} \mathrm{LDH}$ membrane. Initially this membrane was impermeable to any gases unless subject to on-stream thermal activation. After activation, permeances of a series of gas pairs as a $1: 1$ mixture were further measured at $180^{\circ} \mathrm{C}$ and 1 bar. The SF of $\mathrm{H}_{2}-\mathrm{CO}_{2}, \mathrm{H}_{2}-\mathrm{N}_{2}$ and $\mathrm{H}_{2}-\mathrm{CH}_{4}$ mixtures reached 5.8, 9.0 and 13.7 respectively (shown in Table 2), which were considerably higher than their Knudsen values but lower than those of randomly oriented NiAl- $\mathrm{CO}_{3} \mathrm{LDH}$ membranes. The result was reasonable since the interlayer gallery for $\mathrm{ZnAl}-\mathrm{NO}_{3} \mathrm{LDHs}$ $(0.42 \mathrm{~nm})$ was larger than that for $\mathrm{NiAl}-\mathrm{CO}_{3} \mathrm{LDHs}(0.31 \mathrm{~nm})$ so that gas molecules with smaller kinetic diameters like $\mathrm{CO}_{2}$ $(0.33 \mathrm{~nm}), \mathrm{N}_{2}(0.36 \mathrm{~nm})$ and $\mathrm{CH}_{4}(0.38 \mathrm{~nm})$ could permeate through the interlayer gallery more easily.

The relationship between the operation temperature and gas permeation behavior of the $\mathrm{H}_{2}-\mathrm{CH}_{4}$ mixture was further investigated (shown in SI-8†). In the temperature range of $90-210{ }^{\circ} \mathrm{C}$, the $\mathrm{SF}$ of an equimolecular $\mathrm{H}_{2}-\mathrm{CH}_{4}$ mixture first increased with increasing operation temperature, reached the maximum value (13.7) at $180{ }^{\circ} \mathrm{C}$, and then decreased. Meanwhile the $\mathrm{H}_{2}$ permeance increased with temperature and reached the peak value $\left(4.1 \times 10^{-8} \mathrm{~mol} \mathrm{~m}^{-2} \mathrm{~s}^{-1} \mathrm{~Pa}^{-1}\right)$ at $210{ }^{\circ} \mathrm{C}$. Finally the thermal stability of the $\mathrm{ZnAl}-\mathrm{NO}_{3} \mathrm{LDH}$ membrane was tested by the separation of an equimolecular $\mathrm{H}_{2}-\mathrm{CH}_{4}$ mixture at $180{ }^{\circ} \mathrm{C}$ and 1 bar (shown in SI-9†). Both $\mathrm{H}_{2}$ permeance $\left(\sim 3.8 \times 10^{-8} \mathrm{~mol} \mathrm{~m}^{-2}\right.$ $\left.\mathrm{s}^{-1} \mathrm{~Pa}^{-1}\right)$ and $\mathrm{H}_{2}-\mathrm{CH}_{4}$ selectivity $(\sim 14.0)$ were almost unchanged for at least $40 \mathrm{~h}$. The high thermal stability of LDH membranes guaranteed that they were promising to be applied as qualified gas separation membranes.

Besides NiAl- $\mathrm{CO}_{3}$ and $\mathrm{ZnAl}-\mathrm{NO}_{3} \mathrm{LDH}$ membranes, with this method we also tried to prepare CoAl and FeAl LDH membranes on $\gamma-\mathrm{Al}_{2} \mathrm{O}_{3}$ modified $\alpha-\mathrm{Al}_{2} \mathrm{O}_{3}$ substrates. Nevertheless, it was difficult to prepare these membranes in pure and compact

Table $2 \mathrm{H}_{2}$ permeances and SF of $\mathrm{H}_{2}-\mathrm{CO}_{2}, \mathrm{H}_{2}-\mathrm{N}_{2}$ and $\mathrm{H}_{2}-\mathrm{CH}_{4}$ mixtures on the randomly oriented $\mathrm{ZnAl}-\mathrm{NO}_{3} \mathrm{LDH}$ membrane. Operation temperature: $180{ }^{\circ} \mathrm{C}$; feed pressure: 1 bar

\begin{tabular}{llr}
\hline & ${\mathrm{ZnAl}-\mathrm{NO}_{3} \mathrm{LDH} \text { membrane }}$ & \\
\cline { 2 - 3 } System & $\begin{array}{l}\mathrm{H}_{2} \text { permeance } \\
\left(10^{-8} \mathrm{~mol} \mathrm{~m}^{-2} \mathrm{~s}^{-1} \mathrm{~Pa}^{-1}\right)\end{array}$ & $\mathrm{SF}$ \\
\hline $\mathrm{H}_{2}-\mathrm{CO}_{2}$ & 3.6 & 5.8 \\
$\mathrm{H}_{2}-\mathrm{N}_{2}$ & 4.0 & 9.0 \\
$\mathrm{H}_{2}-\mathrm{CH}_{4}$ & 3.7 & 13.7
\end{tabular}


forms. Since both $\mathrm{Co}^{2+}$ and $\mathrm{Fe}^{2+}$ ions were less stable than $\mathrm{Ni}^{2+}$ in aqueous solution, it was thus anticipated that more accurate control over synthesis conditions and a careful selection of mild base would be potentially beneficial for us to fabricate other high quality LDH membranes, which is currently underway.

\section{Conclusions}

$\mathrm{NiAl}-\mathrm{CO}_{3} \mathrm{LDH}$ membranes of different microstructures were prepared on $\gamma-\mathrm{Al}_{2} \mathrm{O}_{3}$-modified porous alumina substrates using the in situ growth method. It was found that the preferred orientation and thickness of LDH layers could be controlled by adjusting the concentration of $\mathrm{CO}_{2}$ dissolved in the precursor solution. Gas permeation results showed that randomly oriented $\mathrm{LDH}$ membranes had much higher $\mathrm{H}_{2}$ selectivity for $\mathrm{H}_{2}-\mathrm{CO}_{2}, \mathrm{H}_{2}-\mathrm{N}_{2}$ and $\mathrm{H}_{2}-\mathrm{CH}_{4}$ mixtures, although in principle the $a b$-oriented LDH membrane was expected to be more suitable for gas permeation since its interlayer gallery was arranged perpendicular to the substrate favouring the minimization of the mass transfer resistance. Several experimental observations such as the selective intercalation of $\mathrm{CO}_{2}$ to the interlayer space and the preferred $a b$-orientation were also found. Particularly it should be noted that due to the preferential adsorption of $\mathrm{CO}_{2}$ in the $\mathrm{LDH}$ layer, there was almost a 3-fold decrease of the $\mathrm{H}_{2}$ permeance for the $\mathrm{H}_{2}-\mathrm{CO}_{2}$ mixture. We further prepared a compact $\mathrm{ZnAl}-\mathrm{NO}_{3} \mathrm{LDH}$ membrane with the mixed gas selectivity higher than Knudsen values but lower than that of a randomly oriented $\mathrm{NiAl}-\mathrm{CO}_{3} \mathrm{LDH}$ membrane owing to the increased gallery height $(0.42 \mathrm{~nm})$ compared with $\mathrm{NiAl}-\mathrm{CO}_{3}$ LDHs $(0.31 \mathrm{~nm})$.

\section{Acknowledgements}

Yi Liu is grateful for the financial support from Alexander von Humboldt Foundation. We gratefully acknowledge financial support by EU CARENA (FP7-NMP-2010-LARGE-4, no. 263007).

\section{Notes and references}

1 (a) Z. P. Lai, G. Bonilla, I. Diaz, J. G. Nery, K. Sujaoti, M. A. Amat, E. Kokkoli, O. Terasaki, R. W. Thompson, M. Tsapatsis and D. G. Vlachos, Science, 2003, 300, 456; (b) T. C. T. Pham, H. S. Kim and K. B. Yoon, Science, 2011, 334, 1533.

2 (a) E. E. McLeary, J. C. Jansen and F. Kapteijn, Microporous Mesoporous Mater., 2006, 90, 198; (b) J. Caro and M. Noack, Microporous Mesoporous Mater., 2008, 115, 215; (c) Y. S. Li and W. S. Yang, J. Membr. Sci., 2008, 316, 3; (d) J. H. Dong, Y. S. Lin, M. Kanezashi and Z. Tang, J. Appl. Phys., 2008, 104, 121301.

3 (a) M. A. Snyder and M. Tsapatsis, Angew. Chem., Int. Ed., 2007, 46, 7560; (b) C. M. Lew, R. Cai and Y. S. Yan, Acc. Chem. Res., 2010, 43, 210; (c) M. Yu, R. D. Noble and J. L. Falconer, Acc. Chem. Res., 2011, 44, 1196.

4 M. Kanezashi, K. Yada, T. Yoshioka and T. Tsuru, J. Am. Chem. Soc., 2009, 131, 414.
5 (a) M. G. Buonomenna, W. Yave and G. Golemme, RSC Adv., 2012, 2, 10745; (b) W. N. W. Salleh, A. F. Ismail, T. Matsuura and M. S. Abdullah, Sep. Purif. Rev., 2011, 40, 261; (c) S. M. Saufi and A. F. Ismail, Carbon, 2004, 42, 241.

6 (a) D. E. Sanders, Z. P. Smith, R. L. Guo, L. M. Robeson, J. E. McGrath, D. R. Paul and B. D. Freeman, Polymer, 2013, 54, 4729; (b) W. N. W. Salleh, A. F. Ismail, T. Matsuura and M. S. Abdullah, Sep. Purif. Rev., 2011, 40, 261; (c) N. Y. Du, H. B. Park, M. M. Dai-Cin and M. D. Guiver, Energy Envrion. Sci., 2012, 5, 7306.

7 (a) H. Bux, F. Y. Liang, Y. S. Li, J. Cravillon, M. Wiebcke and J. Caro, J. Am. Chem. Soc., 2009, 131, 16000; (b) Y. S. Li, F. Y. Liang, H. Bux, A. Feldhoff, W. S. Yang and J. Caro, Angew. Chem., Int. Ed., 2010, 49, 548; (c) A. Huang, H. Bux, F. Steinbach and J. Caro, Angew. Chem., Int. Ed., 2010, 49, 4958.

8 (a) X. L. Dong, K. Huang, S. N. Liu, R. F. Ren, W. Q. Jin and Y. S. Lin, J. Mater. Chem., 2012, 22, 19222; (b) H. L. Guo, G. S. Zhu, I. J. Hewitt and S. L. Qiu, J. Am. Chem. Soc., 2009, 131, 1646.

9 (a) Y. C. Pan and Z. P. Lai, Chem. Commun., 2011, 47, 10275; (b) M. Shah, M. C. McCarthy, S. Sachdeva, A. Lee and H. K. Jeong, Ind. Eng. Chem. Res., 2012, 51, 2179; (c) B. Zornoza, C. Tellez, J. Coronas, J. Gascon and F. Kapteijn, Microporous Mesoporous Mater., 2013, 166, 67.

10 (a) M. Tsapatsis, Science, 2011, 334, 767; (b) K. Varoon, X. Y. Zhang, B. Elyassi, D. D. Brewer, M. Gettel, S. Kumar, J. A. Lee, S. Maheshwari, A. Mittal, C. Y. Sung, M. Cococcioni, L. F. Francis, A. V. McCormick, K. A. Mkhoyan and M. Tsapatsis, Science, 2011, 334, 72.

11 S. P. Koenig, L. D. Wang, J. Pellegrino and J. S. Bunch, Nat. Nanotechnol., 2012, 7, 728.

12 H. Li, Z. N. Song, X. J. Zhang, Y. Huang, S. G. Li, Y. T. Mao, H. J. Ploehn, Y. Bao and M. Yu, Science, 2013, 342, 95.

13 H. W. Kim, H. W. Yoon, S.-M. Yoon, B. M. Yoo, B. K. Ahn, Y. H. Cho, H. J. Shin, H. Yang, U. Paik, S. Kwon, J.-Y. Choi and H. B. Park, Science, 2013, 342, 91.

14 Q. Wang and D. O'Hare, Chem. Rev., 2012, 112, 4124.

15 R. Z. Ma, J. B. Liang, X. H. Liu and T. Sasaki, J. Am. Chem. Soc., 2012, 134, 19915.

16 (a) B. Sels, D. D. Vos, M. Buntinx, F. Pierard, A. K.-D. Mesmaeker and P. Jacobs, Nature, 1999, 400, 855; (b) G. R. Williams and D. O'Hare, J. Mater. Chem., 2006, 16, 3065; (c) S. P. Newman and W. Jones, New J. Chem., 1998, 22, 105; (d) V. Rives and M. A. Ulibarri, Coord. Chem. Rev., 1999, 181, 61; (e) M. Q. Zhao, Q. Zhang, J. Q. Huang and F. Wei, Adv. Funct. Mater., 2012, 22, 675; $(f)$ D. P. Yan, J. Lu, M. Wei, S. H. Qin, L. Chen, S. T. Zhang, D. G. Evans and X. Duan, Adv. Funct. Mater., 2011, 21, 2497.

17 (a) T. W. Kim, M. Sahimi and T. T. Tsotsis, Ind. Eng. Chem. Res., 2008, 47, 9127; (b) T. W. Kim, M. Sahimi and T. T. Tsotsis, Chem. Eng. Sci., 2009, 64, 1585; (c) T. W. Kim, M. Sahimi and T. T. Tsotsis, Ind. Eng. Chem. Res., 2009, 48, 5794.

18 Y. Liu, N. Y. Wang, Z. W. Cao and J. Caro, J. Mater. Chem. A, 2014, 2, 1235. 
19 Z. H. Wang, F. Liu and C. Lu, Chem. Commun., 2011, 47, 5479.

20 X. Zhang, Y. Y. Wu, S. Y. He, D. Z. Yang and F. Li, Thin Solid Films, 2008, 516, 5020.

21 (a) Y. Li, M. Pera-Titus, G. X. Xiong, W. Yang, E. Landrivon, S. Miachon and J.-A. Dalmon, J. Membr. Sci., 2008, 325, 973;

(b) S. Miachon, E. Landrivon, M. Aouine, Y. Sun, I. Kumakiri, Y. Li, O. Pachtová Prokopová, N. Guilhaume, A. GiroirFendler, H. Mozzanega and J.-A. Dalmon, J. Membr. Sci., 2006, 281, 228.

22 M. Wei, X. Y. Xu, X. R. Wang, F. Li, H. Zhang, Y. L. Lu, M. Pu, D. G. Evans and X. Duan, Eur. J. Inorg. Chem., 2006, 2831.

23 H. Y. Chen, F. Z. Zhang, T. Chen, S. L. Xu, D. G. Evans and X. Duan, Chem. Eng. Sci., 2009, 64, 2617.

24 (a) S. Miyata, Clays Clay Miner., 1983, 31, 305; (b) Y. Israëli, G. Taviot-Guého, J.-P. Besse, J.-P. Morel and N. MorelFesrosiers, J. Chem. Soc., Dalton Trans., 2000, 791.

25 A. van der Drift, Philips Res. Rep., 1967, 22, 267.

26 X. X. Guo, S. L. Xu, L. L. Zhao, W. Lu, F. Z. Zhang, D. G. Evans and X. Duan, Langmuir, 2009, 25, 9894.

27 M. Ohyama, H. Kozuka and T. Yoko, Thin Solid Films, 1997, 306, 78.

28 (a) Z. B. Wang and Y. S. Yan, Chem. Mater., 2001, 13, 1101; (b) R. Cai, M. W. Sun, Z. W. Chen, R. Munoz, C. O'Neill,
D. E. Beving and Y. S. Yan, Angew. Chem., Int. Ed., 2008, 47, 525.

29 (a) Y. S. Li, H. Bux, A. Feldhoff, G. L. Li, W. S. Yang and J. Caro, Adv. Mater., 2010, 22, 3322; (b) H. Bux, A. Feldhoff, J. Cravillon, M. Wiebcke, Y. S. Li and J. Caro, Chem. Mater., 2011, 23, 2262.

30 (a) J. Pérez-Ramírez, S. Abelló and N. M. van der Pers, J. Phys. Chem. C, 2007, 111, 3642; (b) L. Li, R. Z. Ma, Y. Ebina, K. Fukuda, K. Takada and T. Sasaki, J. Am. Chem. Soc., 2007, 129, 8000; (c) L. J. Zhang, J. Wang, J. J. Zhu, X. G. Zhang, K. S. Hui and K. N. Hui, J. Mater. Chem. A, 2013, 1, 9046.

31 A. Garcia-Gallastegui, D. Iruretagoyena, V. Gouvea, M. Mokhtar, A. M. Asiri, S. N. Basahel, S. A. Al-Thabaiti, A. O. Alyoubi, D. Chadwick and M. S. P. Shaffer, Chem. Mater., 2012, 24, 4531.

32 S. Ishihara, P. Sahoo, K. Deguchi, S. Ohki, M. Tansho, T. Shimizu, J. Labuta, J. P. Hill, K. Ariga, K. Watanabe, Y. Yamauchi, S. Suehara and N. Iyi, J. Am. Chem. Soc., 2013, 135, 18040.

33 W. S. Yang, Y. Kim, P. K. T. Liu, M. Sahimi and T. T. Tsotsis, Chem. Eng. Sci., 2002, 57, 2945.

34 L. Y. Wang, C. Li, M. Liu, D. G. Evans and X. Duan, Chem. Commun., 2007, 123. 